\title{
The Design of a Computer Simulator to Emulate Pathology Laboratory Workflows
}

\author{
Patterson, M., Bond, R. R., Mulvenna, M., Reid, C., McMahon, F., McGowan, P., Cowan, K., \& Cormican, H. \\ (Accepted/In press). The Design of a Computer Simulator to Emulate Pathology Laboratory Workflows. In \\ Unknown Host Publication Association for Computing Machinery. https://doi.org/10.1145/2970930.2970956
}

Link to publication record in Ulster University Research Portal

\author{
Published in: \\ Unknown Host Publication
}

\section{Publication Status:}

Accepted/In press: 02/05/2016

DOI:

10.1145/2970930.2970956

\section{Document Version}

Author Accepted version

\section{General rights}

Copyright for the publications made accessible via Ulster University's Research Portal is retained by the author(s) and / or other copyright owners and it is a condition of accessing these publications that users recognise and abide by the legal requirements associated with these rights.

\section{Take down policy}

The Research Portal is Ulster University's institutional repository that provides access to Ulster's research outputs. Every effort has been made to ensure that content in the Research Portal does not infringe any person's rights, or applicable UK laws. If you discover content in the Research Portal that you believe breaches copyright or violates any law, please contact pure-support@ulster.ac.uk. 


\title{
The Design of a Computer Simulator to Emulate Pathology Laboratory Workflows
}

\author{
M. Patterson, R. Bond, M. Mulvenna, C. Reid, F. McMahon, P. \\ McGowan \\ Ulster University \\ Belfast, N. Ireland \\ \{m.patterson | rb.bond | md.mulvenna | ci.woodside | fc.mcmahon | \\ p.mcgowan\}@ulster.ac.uk
}

\author{
K. Cowan, H. Cormican \\ Cirdan Imaging Ltd. \\ Lisburn, N. Ireland \\ $\{$ kcowan | \\ hcormican\}@cirdan.com
}

\begin{abstract}
This paper outlines the design of a simulator to allow for the optimisation of clinical workflows within a pathology laboratory and to improve the laboratory's efficiency in the processing, testing, and analysis of specimens. The aim of this research project is to determine whether the simulator can improve clinical workflows since it's design is based on relevant human factors and cognitive ergonomics in mind. Often pathologists have difficulty in pinpointing and anticipating issues in the clinical workflow until tests are running late or in error. It can be difficult to pinpoint the cause and even more difficult to predict any issues which may arise. For example, they often have no indication of how many samples are going to be delivered to the laboratory that day or at a given hour. If we could model scenarios using past information and also the 'live' known variables, it would be possible for pathology laboratories to prepare the appropriate resources, e.g. the printing of specimen labels or to activate a sufficient number of technicians. This would expedite the clinical workload, clinical processes and improve the overall efficiency of the laboratory. The simulator will also be used for the purposes of training new staff on the workflow and practices of the laboratory.
\end{abstract}

\section{CCS Concepts}

- Computing methodologies Modeling methodologies

\section{Keywords}

Computer simulation, laboratory process, optimization, pathology, workflow

\section{INTRODUCTION}

The aim of this paper is to discuss the potential for the creation of a simulator which could optimise the workflow within a clinical laboratory. To do this, the paper is split into several sections. The first section discusses the background and the current workflow process that is common within most laboratories. The second section discusses issues that pathologists often face when using current practices. The next section will discuss the potential requirements for the simulator in order to combat theses issues. There will be a section discussing the potential design of the

Permission to make digital or hard copies of all or part of this work for personal or classroom use is granted without fee provided that copies are not made or distributed for profit or commercial advantage and that copies bear this notice and the full citation on the first page. Copyrights for components of this work owned by others than ACM must be honored. Abstracting with credit is permitted. To copy otherwise, or republish, to post on servers or to redistribute to lists, requires prior specific permission and/or a fee. Request permissions from Permissions@acm.org.

ECCE '16, September 05-08, 2016, Nottingham, United Kingdom

(C) 2016 ACM. ISBN 978-1-4503-4244-5/16/09...\$15.00

DOI: http://dx.doi.org/10.1145/2970930.2970956 simulator, taking into account the user interface and some of the technical implementation required. Finally, there will be some discussion on additional benefits of the simulator.

\section{RELATED WORK}

Simulators are being used more and more within the healthcare profession, both for training purposes and for the visualization of data in a laboratory setting. The use of these simulators has "revolutionized medical practice" [1] as it allows staff to experience various situations in a safe and risk free environment. Studies have shown that the use of simulators in training provide a positive effect on knowledge gain [2].

Research was carried out into the visualization of data within a radiotherapy clinic in order to optimise the workflow. This study showed that the addition of this visualization affectively assisted the work of the users and considerably increased the efficiency of the clinic[3].

\section{BACKGROUND AND CURRENT PRACTICES}

The workflow of a laboratory involves a sequence of different stages that are carried out to analyse specimens and generate a report that details the results of this analysis. This workflow, however, can differ within different pathology laboratories, as each will have its own specialism and unique way of processing specimens. The main aim of this section is to look generally at laboratory workflow and to develop a clear understanding of a number of broad categories which the majority of laboratory workflows incorporate. These categories are as follows: (1) Specimen Reception, (2) Testing, (3) Validation, (4) Approval, and (5) Reporting.

Some laboratories will use a paper-based system of recording and tracking specimens through these stages. Others will use technological methods such as Laboratory Information Systems (LIS). The anticipation is that this simulator will be used in conjunction with a LIS.

\subsection{Specimen Reception}

This is the initial stage of the process within the majority of laboratories. When a test or series of tests is ordered a sample specimen will be collected from the patient. This specimen will then be delivered to the laboratory in order for the tests to be carried out. When the specimen arrives in the laboratory, it will pass through a specimen reception. This will allow the specimen to be logged into the laboratory and can be marked as received. In paper-based systems, the specimen will be accompanied by a slip of paper outlining the details of the patient and which test or tests are to be performed. In more technological systems, the specimen will have a barcode attached that can be scanned into the LIS or 
another computer-based system. This will provide the patient and test details.

\subsection{Testing}

The specimen is then passed into the testing phase. This stage in the process will vary greatly in various laboratories. For example, smaller laboratories often perform all their testing manually, while larger laboratories will have an automated testing process. Depending on the type of specimen, it may require initial observation by a pathologist, or it may be placed directly into an instrument. The pathologist may make notes on various observations of the specimen. In a paper-based system, these notes will be hand written and will accompany the original notes sent with the sample whereas in a LIS, these will be typed notes.

\subsection{Validation}

Once testing has completed, the results are passed to the validation stage. In some cases, the results are validated automatically by the instrument which performs the test. Parameters can be set up to signify a normal range for the results. If the result falls outside this range, it will require validation from a pathologist before the specimen can pass to the next stage in the process. In some laboratories, the results will always be passed to a pathologist.

\subsection{Approval}

Once the results have been validated, often a preliminary report is generated. If the results are being validated by instruments, it can be common for this preliminary report to be passed to a pathologist or consultant to review the results. This can also occur where a second opinion is required before the report can be released.

\subsection{Reporting}

Once the test results have been approved, the report can then be released to the requesting physician. In a paper-based system, this may need to be generated manually. Typically, reports are posted or faxed as opposed to being emailed.

\section{ISSUES}

Within the stages outlined above, there are several issues and problems which can occur. These vary in their severity and in the impact they can have on the entire workflow. It is important to understand these issues so that the simulator can attempt to alleviate them as far as possible. Table 1 lists the common issues and ranks their severity.

Table 1 the issues faced by pathologists in a typical laboratory workflow and their severity.

\begin{tabular}{l|l|l}
$\begin{array}{l}\text { Issue } \\
\text { Number }\end{array}$ & Description & Severity \\
\hline 1 & $\begin{array}{l}\text { Being unsure of the number of samples } \\
\text { that will be delivered to the laboratory. } \\
\text { Checking in specimens can be a long } \\
\text { process. }\end{array}$ & High \\
3 & $\begin{array}{l}\text { Being unable to determine the number of } \\
\text { specimens at each stage of the process. } \\
\text { Being unable to identify where there are } \\
\text { bottlenecks in the system. } \\
\text { Being unable to tell when specimens } \\
\text { could be potentially late. } \\
\text { Being unable to determine the number of } \\
\text { specimens in error. }\end{array}$ & High \\
& \multicolumn{2}{l}{ High }
\end{tabular}

4.1 Issue 1: Being unsure of the number of samples that will be delivered to the laboratory

Under current workflows, many laboratories are not aware of how many specimens they may receive in a single delivery. This can have implications as to how quickly the specimens can be passed through the workflow process. For example, if an epidemic broke out, the laboratory may not be aware and, as a result, could be severely understaffed to cope with the extra level of specimens requiring processing. The optimisation of staff and resources is key to improving overall laboratory efficiency [4].

\subsection{Issue 2: Checking in specimens can be a long process}

Often, deliveries to a laboratory only occur once or twice a day. As a result, there can often be hundreds or in the case of larger laboratories, even thousands of specimens to check and log before they can be passed onto the testing stage. This can be a long and often high pressured task as, if the processing is not carried out in a sufficient time, the specimens will be late passing through the rest of the workflow.

\subsection{Issue 3: Being unable to determine the number of specimens at each stage of the process}

While some laboratories may be aware of the total number of specimens passing through the workflow, most do not know how many specimens are within each stage of the process at any one time. This can lead to large numbers of specimens being in a particular stage, with fewer specimens at other stages causing an imbalance within the workflow.

\subsection{Issue 4: Being unable to identify where there are 'bottlenecks' in the system}

If specimens are reported late, there is usually an underlying cause somewhere within the workflow. This is often caused by specimens being slow to move through a particular stage of the process, also referred to as a 'bottleneck'. Being able to determine where these 'bottlenecks' are in the system would potentially have an impact in reducing the number of specimens reported late as the cause could be investigated. For example, if there was a 'bottleneck' in the testing stage, it may be caused by an instrument failure.

\subsection{Issue 5: Being unable to tell when specimens could be potentially late}

Most laboratories have a target turnaround time for processing specimens. Many have calculated the average time it takes for a specimen to pass through a particular stage of the process. If the specimen takes longer to pass through a particular stage, it could have the potential to be reported late. If this information was made available, those working in a stage further along in the process may be able to process a potentially late specimen quickly so the results can be reported on time.

\subsection{Issue 6: Being unable to determine the number of specimens in error}

Occasionally, a specimen may fail to pass through a particular stage in the process. This specimen is then said to be 'in error'. It is possible for this specimen to go unnoticed until it has not been reported on time. If there was a method for displaying those specimens which are in error, they could be corrected more quickly. It could also be the case that if there is a significant issue 
within one of the stages, it can be dealt with before many specimens are placed in error.

\section{SIMULATOR REQUIREMENTS}

In order to help alleviate the issues discussed above, a workflow simulator will be designed. In order to ensure the simulator can better illustrate the workflow of a laboratory, and therefore allow maximum access to all the relevant information required to manage the laboratory workflow [5], a series of requirements has been outlined. These are discussed below.

\subsection{Indicating the number of specimens in a delivery}

If the simulator can indicate the number of specimens that are to be delivered in a single delivery, and perhaps even the time the delivery is due, it would give the laboratory the opportunity to make some advanced preparations. If the quantity of specimens is higher than normal, they would have the opportunity to organise the scheduling of extra staff members to cope with the increased workload.

Preparations could also be made for the retrieval of the specimens, such as pre-printing barcode labels to attach to the specimen containers. If there are specimens which require urgent processing, these can be given priority.

\subsection{Showing how many specimens are at each stage}

A graph showing the number of specimens currently within each stage of the process would help to prevent 'bottlenecks' from occurring. This would allow for forward planning in the case that there are a large number of samples about to move from one stage to the next. For example, if a significant number of samples were currently in the testing stage and about to move to the validation stage, staff cold be coordinated to begin validating the results as they come in.

\subsection{Showing the flow between stages}

Directional arrows and a traffic light colour-coding system could be used to indicate the level of flow through and between each stage (green for normal flow, orange for slow flow, and red for critical flow). This will allow pathologists to clearly see where there are issues and 'bottlenecks' in the process.

\subsection{Indicating if specimens are potentially late or in error}

Using a graph or chart to indicate the number of specimens that have the potential to be late, or those that are in error, would help to improve the overall efficiency of the laboratory. The issues surrounding these potentially late or in error specimens could be dealt with more effectively as currently, laboratory staff have no way of telling whether samples will be late.

\section{SIMULATOR DESIGN}

In order for the simulator to meet its requirements, it needs to be carefully designed. The two main areas which need to be carefully considered are the user interface and the technical implementation. Figure 1 depicts the user interface of the simulator.

\subsection{User interface}

The simulator will incorporate a user interface consisting of an effective data visualisation dashboard. It will depict the movement of specimens through the various stages of the process, as well as the number of specimens at each stage. This movement will be visualised using an animated flow diagram that is updated in real time.

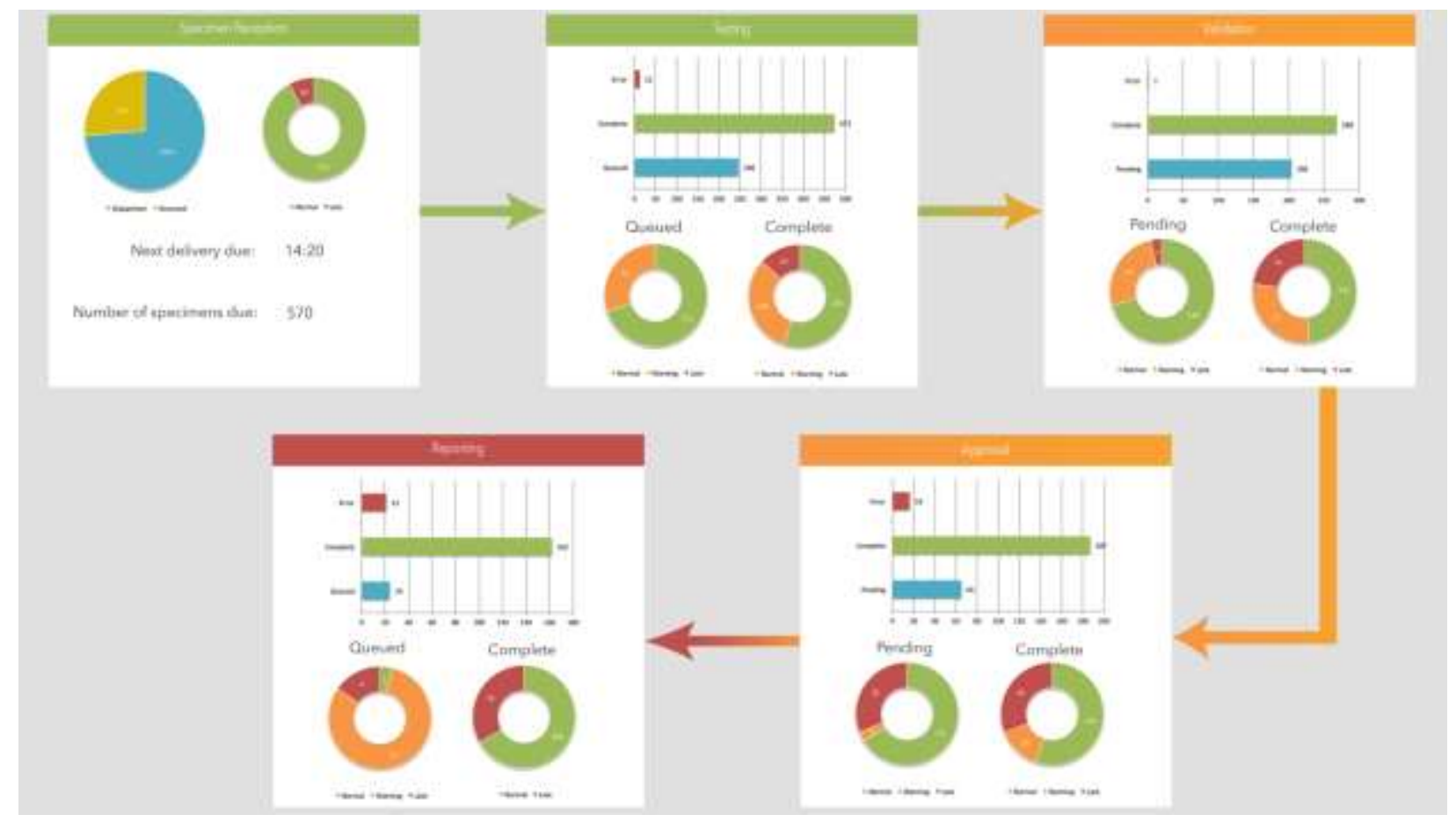

Figure 1. A mockup of a potential layout for the simulator. Each step in the process is placed inside an individual container. Arrows are used to indicate the flow through the process. (a) Specimen Reception (b) Testing (c) Validation (d) Approval (e) Reporting. 
Charts and graphs will be used to indicate the status of specimens at each stage of the process. For example, a doughnut chart could show the percentage of specimen tests that are on time, potentially late, and late. Additionally, a graph could be used to indicate the number of specimens pending, complete and in error.

Clicking on potentially late samples, or samples in error, will display more detailed information about those samples, the tests that still need to be performed on them and their urgency level. This would allow any issues to be resolved quickly. In the case of potentially late samples, this could help to ensure that critically needed results are delivered on time.

\subsection{Technical implementation}

The simulator will be created as a web application. Emerging web technologies, such as HTML5, CSS, and JavaScript, will be used to create the flow diagram showing the workflow of the laboratory.

JavaScript will be used to program the business logic and animate the movement of samples through each of the stages in real time. This live information will be extracted from a relational database.

A charting library will also be required to create and update the graphs and charts in real time. This could be achieved by converting the data extracted from the database into JavaScript Object Notation (JSON) and then fed into the charting library via Asynchronous JavaScript And XML (AJAX).

\section{DISCUSSION}

As well as being used in a real laboratory situation, the simulator could also be used for training purposes as the use of simulators for training purposes has been shown to improve task success and completion rates [6]. 'Bots' would be used to control the flow of specimens through each step of the process. Like existing software agents technology, these bots would be configurable in order to simulate different situations, which may arise in a laboratory such as an emerging epidemic. The bots could then be turned on and off to allow trainees to complete the tasks required at that step of the process, for example validating test results.

\section{CONCLUSION}

This paper has discussed the current workflow process within present within many laboratories, and some of the issues that exist within these current processes. The requirements and design of the simulator were outlined and discussed in detail, as well as the potential for the use of the simulator as a training tool within a clinical laboratory setting.

\section{REFERENCES}

[1] Toader, E., Clinical Simulations for Learning Medical Skills: A Work-based Approach to Simulators, Procedia - Social and Behavioral Sciences, Volume 197, 25 July 2015, Pages 2443 2448 ,

[2] Kleinert, R., Heiermann, N., Plum, P., et al. (2015) 'WebBased Immersive Virtual Patient Simulators: Positive Effect on Clinical Reasoning in Medical Education', Journal Of Medical Internet Research, 17(11), p. 1.

[3] Kirrmann S, Gainey M, Röhner F, et al. 2015. Visualization of data in radiotherapy using web services for optimization of workflow. Radiation Oncology (London, England)

[4] Covill, L. 2015. The LEAN lab: automation, workflow, and efficiency Medical Laboratory Observer, vol. 47, no. 2, pp. $8-8,10,12$.

[5] McDonald, D. 2013. Optimizing Laboratory Workflow. In: Immunohistochemical Staining Methods, Denmark: Dako, pp. 122-131.

[6] Griswold-Theodorson, S, Ponnuru, S, Dong, C, Szyld, D, Reed, T, \& McGaghie, W 2015, 'Beyond the simulation laboratory: a realist synthesis review of clinical outcomes of simulation-based mastery learning', Academic Medicine: Journal Of The Association Of American Medical Colleges, 90, 11, pp. 1553-1560, MEDLINE, EBSCOhost, viewed 28 February 2016. 